\title{
Universal Pathogen-Reduced Plasma in Elective Open-Heart Surgery and Liver Resection
}

\author{
Biarte G. Solheim, MD, PhD, MHA
}

\begin{abstract}
$A B O$-incompatible transfusions and transfusion-related lung injury are today the leading transfusion-related causes of death in the developed world. Since anti-A and anti-B antibodies in plasma can give rise to serious, even fatal, transfusion reactions, $\mathrm{ABO}$-identical/compatible plasma is indicated, but presents a logistical challenge and a risk for transfusion of incorrect plasma. In an effort to circumvent these problems, an ABO-independent universally applicable, pathogen-reduced plasma, Uniplas, has been developed and proven safe and efficacious for use in adults through prospective, randomized, controlled open-heart surgery studies and in prospective, parallel group, controlled liver resection studies. The results of these trials are presented and discussed in relation to solvent/detergent (SD) treated plasma, in general.
\end{abstract}

The cost effectiveness of pathogen-reduced plasma is low because of the very low risk for transfusion transmitted viral infections in the developed world (US $\$ 2$ to $\$ 9$ million per quality-adjusted life year). However, taking into account the combined safety of Uniplas with regard to transfusion-related lung injury, pathogen reduction and independence of $A B O$ blood groups, the cost per gained life year is reduced to US $\$ 40,000$ to $\$ 100,000$.

Keywords: $\mathrm{ABO}$ blood-group system; Universal ABO-independent plasma; Pathogen reduction; Blood transfusion; Open-heart surgery; Liver resection; Cost-effectiveness

$\mathrm{T}$ ransfusion of $\mathrm{ABO}$-incompatible blood components/ products results in serious, often fatal transfusion reactions. ABO-incompatible transfusions and transfusion-related acute lung injury are today the leading transfusion-related causes of death in the developed world. ${ }^{1}$ Anti-A or anti-B antibodies in donor plasma may destroy blood group A, B or $\mathrm{AB}$ red blood cells (RBCs) after transfusion (minor $\mathrm{ABO}$ incompatibility). However, such reactions are far less frequent and generally less severe after transfusion of incompatible plasma than after transfusions of mismatched RBCs (major ABO incompatibility). ${ }^{2}$ The antibody titer, administered volume and administration speed of plasma are all factors of importance for the severity of the reaction, as antibodies in the transfused plasma are rapidly diluted and neutralized by free A and B antigens, possible anti-idiotypic antibodies and numerous antigen bearing cells in the blood and tissues of the recipient. ${ }^{3,4}$ However, because anti-A and

Reprint Requests: Bjarte G. Solheim, MD, PhD, MHA, Institute of Immunology, Rikshospitalet - Radiumhospitalet Medical Center, University of Oslo, NO-0027 Oslo, Norway. Tel.: +47 2307 3007, Fax: +47 2307 35l0, E-mail: bjagees@online.no
anti-B antibodies in plasma can result in dosage dependent serious, even fatal, transfusion reactions, ${ }^{5}$ ABO-identical/ compatible plasma is indicated for transfusion complicating logistics and increasing the risk for transfusion of incorrect plasma. ${ }^{6}$ Solvent/detergent (SD) treated plasma of blood group AB (Octaplas, Octapharma AG, Lachen, Switzerland), which contains neither anti-A nor anti-B antibodies, has been successfully used for more than 10 years in emergency transfusions in Norway, irrespective of the patient's ABO blood group. ${ }^{7}$ However, because the availability of blood group AB plasma is limited in Caucasians (4\%), a universal plasma is an interesting alternative as it would make transfusions logistically easier and would be useful in emergency cases and in worst case scenarios, such as war.

Universally applicable lyophilized plasma, prepared from pools of random plasma, was used during World War II by Allied Forces, and has been registered in the United Kingdom, ${ }^{8}$ as well as in other European countries, for use in 
Table 1. Biochemical characterization of Uniplas compared to Octaplas and quarantine fresh-frozen plasma.

\begin{tabular}{|c|c|c|c|}
\hline \multirow[b]{2}{*}{ Parameters } & \multicolumn{3}{|c|}{ Mean (min-max) } \\
\hline & Uniplas* & $\begin{array}{l}\text { Octaplas } 17 \\
\qquad(n=12)\end{array}$ & $\begin{array}{l}\text { Quarantine FFP17 } \\
\qquad(\mathrm{n}=12)\end{array}$ \\
\hline Total proteins [mg/ml] & $57(53-60)$ & $55(54-57)$ & $57(50-61)$ \\
\hline Fibrinogen [mg/ml] & $2.5(2.3-2.9)$ & $2.5(2.4-2.6)$ & $2.6(1.9-3.6)$ \\
\hline Factor II [IU/ml] & $0.80(0.74-0.84)$ & $0.83(0.79-0.86)$ & $0.88(0.77-1.18)$ \\
\hline Factor V [IU/ml] & $0.89(0.60-1.00)$ & $0.78(0.75-0.84)$ & $0.90(0.73-1.50)$ \\
\hline Factor VII [IU/ml] & $1.03(0.92-1.20)$ & $1.08(0.90-1.17)$ & $0.95(0.67-1.38)$ \\
\hline Factor VIII [IU/ml] & $0.75(0.60-0.90)$ & $0.68(0.51-0.78)$ & $0.76(0.52-1.13)$ \\
\hline Factor IX [IU/ml] & $0.96(0.70-1.19)$ & $0.96(0.86-1.06)$ & $1.02(0.82-1.28)$ \\
\hline Factor X [IU/ml] & $0.88(0.73-0.97)$ & $0.78(0.75-0.80)$ & $0.79(0.62-0.99)$ \\
\hline Factor XI [IU/ml] & $1.10(0.90-1.30)$ & $0.99(0.91-1.04)$ & $1.13(0.96-1.80)$ \\
\hline Factor XII [IU/ml] & $0.86(0.85-0.93)$ & $0.84(0.74-0.89)$ & $0.82(0.45-1.12)$ \\
\hline Factor XIII [IU/ml] & $1.11(0.99-1.23)$ & $1.08(1.05-1.11)$ & $1.06(0.68-1.69)$ \\
\hline vWF (Rcof) [IU/ml] & $0.74(0.67-0.80)$ & $0.76(0.63-0.91)$ & $0.89(0.77-0.98)$ \\
\hline aPTT [sec] & $30.7(30.0-33.0)$ & $35.2(33.8-36.9)$ & $35.2(31.7-42.5)$ \\
\hline Protein C [IU/ml] & $0.82(0.71-0.88)$ & $0.85(0.81-0.87)$ & $0.89(0.79-1.05)$ \\
\hline Protein S [IU/ml] activity & $0.56(0.42-0.62)$ & $0.64(0.55-0.71)$ & $1.03(0.71-1.39)$ \\
\hline Plasmin inhibitor [IU/ml] & $0.32(0.27-0.34)$ & $0.23(0.20-0.27)$ & $1.04(0.95-1.18)$ \\
\hline Anti-thrombin [IU/ml] & $0.91(0.88-0.95)$ & $0.94(0.90-0.97)$ & $1.06(0.77-1.23)$ \\
\hline
\end{tabular}

FFP, fresh-frozen plasma. vWF, von Willebrand factor. aPTT, activated partial thromboplastin time

${ }^{*}$ Batch release data

emergency situations where it simplifies the logistics. However, this lyophilized plasma represents a high risk of transfusion-transmitted hepatitis. Uniplas, a pathogen reduced frozen universal plasma, was developed by Octapharma (Octapharma Pharmazeutika, PPGmbH, Vienna, Austria) and is made by proportionally pooling A, B and AB plasma in order to neutralize anti-A and anti-B antibodies with $\mathrm{A}$ and $\mathrm{B}$ antigens and possible anti-idiotypic antibodies in the plasma. ${ }^{3,4}$ Plasma of blood group $\mathrm{O}$ is not used because of its generally higher anti-A and anti-B $\operatorname{IgM}$ titre, increased content of immune anti-A and anti-B IgG, lack of neutralizing $\mathrm{A}$ and $\mathrm{B}$ antigens, and low levels of coagulation factor VIII and von Willebrand factor (vWF). A similarly pathogen-reduced, universal lyophilized product, Bioplasma FDP, has been produced by the National Bioproducts Institute in South Africa by random pooling of low-titered plasma of all ABO blood types. ${ }^{9}$ Pathogen reduction is achieved by SD treatment, ${ }^{10}$ which is a well-documented and extremely effective method to eliminate enveloped viruses from plasma and plasma products. ${ }^{10,11}$ Potentially present nonenveloped viruses, such as hepatitis A virus and parvovirus B19, are not affected by SD treatment, but inhibited by neutralizing antibodies in the plasma pool and final product. ${ }^{12}$

SD-treated plasma has been used in Europe since 1991 and, to date, more than 6 million units $(200 \mathrm{ml} / \mathrm{unit})$ have been transfused. Octaplas has been the most widely used product ( $>4.4$ million units sold since launch). In the US, the SD-treated plasma named, PLAS+SD (Vitex, Watertown, MA), was licensed in 1998, but has subsequently been withdrawn from the market. In spite of the fact that both products are SD-treated by similar methods, significant product differences, ascribed to production methods and type of plasma used, have been reported. ${ }^{13,14,15}$ Such differences could explain the complications observed in the US. ${ }^{15}$ In Europe, three prospective, randomized and three observational studies have demonstrated a similar clinical efficacy of SD-treated plasma and fresh-frozen single donor plasma in various clinical settings. ${ }^{16}$ Although the clinical studies included only 376 patients, and therefore lacked the statistical power to detect minor differences, the results demonstrate that reductions in coagulation factor and inhibitor levels caused by SD treatment did not impair clinical efficacy. Furthermore, the concerns about low levels of plasmin inhibitor and protein $\mathrm{S}$ were not confirmed in the clinical studies.

Table 1 compares the specifications for Uniplas and Octaplas. ${ }^{17}$ Except for a consistent presence of low titer anti-A and anti-B in Uniplas when compared to the blood group-specific Octaplas (A, B or $\mathrm{O}$ ), their specifications are virtually identical. This review describes the experience with Uniplas and focuses, in particular, on its safety with regard to hemolytic transfusion reactions attributable to low residual amounts of anti-A and anti-B antibodies. 


\section{Uniplas}

Since 1999, ten batches of Uniplas have been manufactured by Octapharma. Batches of 380 liters were produced from 1000 units to 1520 units of fresh-frozen plasma, dependent on the ratio between recovered and apheresis plasma. According to product specifications and testing of each batch, the ABO blood-group specific antibody titer of Uniplas (diluted in saline) was $<8$ for anti-A and anti-B IgM antibodies (agglutination at room temperature) and $<32$ for anti-A and anti-B IgG antibodies (as determined by indirect antiglobulin technique). Binding of anti-A and anti-B antibodies to A- and $\mathrm{B}$-antigens in plasma did not increase the level of immune complexes above normal range in fresh-frozen plasma as monitored by formation of the complement immune complexes (CIC) binding $\mathrm{C} 1 \mathrm{q}$ (CIC-C1q) and C3 (CIC-C3) (A. Heger, Octapharma, personal communication). Total protein and fibrinogen levels as well as coagulation factor and protease inhibitor activities in Uniplas are compared to Octaplas and quarantine fresh-frozen plasma in table $1 .{ }^{17}$ The concentration and activity of the different proteins are similar for Uniplas and Octaplas and are within the reference ranges for quarantine fresh-frozen plasma, except for protein $\mathrm{S}$ and plasmin inhibitor. As a result of SD treatment during manufacturing, protein $\mathrm{S}$ and plasmin inhibitor levels are reduced compared with the original fresh-frozen plasma pools by approximately $40 \%$ and $70 \%$, respectively. In Uniplas and Octaplas, the multimeric pattern of vWF is normal, except for a slight reduction of the largest multimers; however, vWF-cleavage protease activity (ADAMTS13) is comparable to fresh-frozen plasma (A Heger, Octapharma, personal communication). After thawing, Uniplas had a stable content of coagulation factors and inhibitors for 4 hours at room temperature and 8 hours at $4^{\circ} \mathrm{C}$, which is similar to Octaplas. ${ }^{18}$

\section{Clinical Studies}

Open-heart surgery study 19,20 $^{10}$

The study was performed as a prospective, parallel group, randomized, controlled study comparing Uniplas and Octaplas in open-heart surgery at a tertiary university hospital. Eighty-four patients undergoing open-heart surgery (including coronary artery bypass, valvular surgery, or combined artery bypass and valvular surgery) were enrolled into the study and monitored up to day 3 postoperatively, where after they generally were transferred to their local secondary level hospital. Patients were randomized 2:1 to receive Uniplas or Octaplas $\mathrm{AB}$, respectively, if plasma transfusion was needed during surgery or the following two days. Assignment to study group was performed by the drawing of sealed envelopes.

\section{Elective liver resection study ${ }^{21}$}

The study was performed as an open-label, parallel-group controlled, non-randomized phase III study involving six European hospitals. Liver surgery was performed according to local state-of-the-art techniques. One hundred and twenty-two

Table 2. Criteria for inclusion or exclusion from open-heart surgery and liver resection studies.

\begin{tabular}{|c|c|c|}
\hline & Open-heart surgery & Liver resection \\
\hline \multicolumn{3}{|l|}{ Inclusion criteria } \\
\hline \multicolumn{3}{|l|}{ Age: } \\
\hline$>18$ years & $\mathrm{x}$ & \\
\hline$>18$ years but $<70$ years & & $\mathrm{x}$ \\
\hline Male & $\mathrm{x}$ & $\mathrm{x}$ \\
\hline Female & $x$ & $\mathrm{x}$ \\
\hline Elective surgery & $x$ & $\mathrm{x}$ \\
\hline Provide informed consent & $\mathrm{x}$ & $\mathrm{X}$ \\
\hline \multicolumn{3}{|l|}{ Exclusion criteria } \\
\hline Unstable angina pectoris & $\mathrm{x}$ & \\
\hline Known liver cirrhosis or liver transplant & & $\mathrm{X}$ \\
\hline Require immunosuppressive therapy & & $\mathrm{x}$ \\
\hline Exposure to viral hepatitis during last 6 months & $\mathrm{X}$ & $\mathrm{x}$ \\
\hline Hypersensitivity to blood products & $\mathrm{x}$ & $\mathrm{x}$ \\
\hline IgA deficiency with documented antibodies against IgA & $\mathrm{x}$ & $\mathrm{x}$ \\
\hline Exposure to blood products within 30 days of surgery & & $\mathrm{x}$ \\
\hline History of or suspected drug use & $\mathrm{x}$ & $x$ \\
\hline Pregnant of nursing women & $x$ & $x$ \\
\hline Participation in another clinical study concurrently or within last 3 months & $\mathrm{x}$ & $\mathrm{x}$ \\
\hline
\end{tabular}


patients undergoing a planned liver resection were included to receive Uniplas if in need of plasma. Patients were monitored up to day 7 postoperatively.

Both the open heart surgery and the liver resection studies were conducted in accordance with the Declaration of Helsinki (update: Edinburgh, Scotland, October 2000) and Good Clinical Practice guidelines, as set out in the Notes for Guidance on Good Clinical Practice (CPMP/ICH/135/95). Regulatory and ethical approval was obtained in accordance with local requirements, and informed consent was obtained from each patient. Data quality was affirmed by independent auditors monitoring the clinical studies.

The aim of these studies was to investigate the safety and efficacy of Uniplas in patients undergoing elective open heart-surgery or liver resection. The open heart-surgery study was performed first, followed by the liver resection study in order to assess the safety of larger transfusion volumes of Uniplas.

\section{Study Protocol}

Patients

Patients of blood groups A, B or AB (group "A-B-AB") were at risk for hemolysis due to the low titer anti-A and anti-B antibodies present in Uniplas, while patients of blood group $\mathrm{O}$ were not at risk and therefore served as controls (group "O”). In order to compare Uniplas with Octaplas, patients with any ABO blood group were included in the open-heart surgery study to receive Octaplas from blood group AB. Both studies also included a group not requiring any plasma transfusion. Patient selection criteria are shown in table 2. The studies were observer-blinded with respect to all laboratories, but not to the administrator of the study drug.

\section{Uniplas administration}

Uniplas was administered in volumes of $200 \mathrm{mls}$ (1 unit), after having been thawed at $37^{\circ} \mathrm{C}$ immediately prior to transfusion. Local guidelines for plasma transfusion were adhered to. Results of coagulation tests were taken into account, if available to the surgeon, when transfusion was decided. The actual dose of Uniplas administered was dependent on the individual circumstances and entirely at the clinician's discretion. In general, $10 \mathrm{ml} / \mathrm{kg}$ to $20 \mathrm{ml} / \mathrm{kg}$ were given as a starting dose. In open heart-surgery, a dose of 5 $\mathrm{ml} / \mathrm{kg}$ to $8 \mathrm{ml} / \mathrm{kg}$ was given at the end of cardiopulmonary bypass for acute reversal of Warfarin effect, if plasma was not otherwise indicated.

\section{Blood sampling and vital sign monitoring}

Time points for blood sampling and vital sign monitoring are indicated in table 3 . In order to achieve standardization in the multicenter liver resection study, the following key parameters were analyzed at a central laboratory in Germany: direct antiglobulin test (DAT), C3b and terminal complement complex (TCC), free hemoglobin in serum, fibrinogen, activated partial thromboplastin time (aPTT), international normalized ratio (INR) and haptoglobin. Due to courier failure a shipment from one hospital was lost. In the liver resection study, blood samples for DAT were collected in tubes containing anticoagulant citrate phosphate dextrose adenine solution (CPDA) and stored at $4^{\circ} \mathrm{C}$ to $10^{\circ} \mathrm{C}$ for up to 3 weeks before testing, while samples for complement testing were collected as whole blood and the serum stored at $-70^{\circ} \mathrm{C}$ until testing. In the open heart-surgery study, EDTA blood samples were stored at room temperature before DAT (within 24 hours), while samples for complement factors were promptly cooled on ice, separated and the plasma frozen at $-70^{\circ} \mathrm{C}$ until testing.

\section{Adverse events monitoring}

From the start of surgery until the last observation day, all adverse events were recorded according to the Medical Dictionary for Regulatory Activities, version 5.1 (MedDRA), with special emphasis on hemolytic and allergic reactions. Concomitant medications were also recorded.

\section{Safety and efficacy measurements}

Monitoring of hemolysis

DAT with the DiaMed-IDMicro Typing System (DiaMed, Cresier, Switzerland) was used to measure ABO incompatibility. In the open-heart surgery studies, DAT reactions were graded from + to ++++ . In the liver resection study, DAT was only registered as positive or negative. In addition, hemolysis was evaluated by measurement of free hemoglobin in serum and haptoglobin.

\section{Complement activation}

Quantification of C3b and TCC was performed using enzyme immunoassay procedures utilizing monoclonal antihuman immunoglobulin specific for $\mathrm{C} 3 \mathrm{~b}$ or TCC. In the open-heart studies, a validated in-house method 22,23 was applied, while in the liver resection study a commercial kit (Quidel, San Diego, CA) was used.

\section{Efficacy}

Efficacy was monitored by the coagulation parameters. Activated partial thromboplastin time (aPTT) and fibrinogen concentration were measured in both studies. Prothrombin time (expressed as INR) and protein $\mathrm{C}$ levels (chromogenic assay) were additionally measured in the liver resection study. Activated clotting time was included in the open-heart surgery studies, as this was a standard test in connection with the cardiac surgery.

\section{Statistical methods}

Mean and standard deviation, median and range were calculated. Univariate analysis was done by Chi-square test for categorical variables. Mann-Whitney test was applied for continuous variables. Analysis of variance was used to test differences, and $\mathrm{P}$ values of $<0.05$ were considered significant.

\section{Results}

Open-heart surgery study ${ }^{19,20}$

Of the 55 plasma-transfused patients, Uniplas was given to 25 
Table 3. Sampling and study procedures.

\begin{tabular}{|c|c|c|c|c|c|c|c|c|}
\hline Adverse events & $\begin{array}{l}\text { Pre- } \\
\text { surgery }\end{array}$ & $\begin{array}{l}\text { Pre- } \\
\text { transfusion }\end{array}$ & $\begin{array}{l}\text { Post- } \\
\text { transfusion }\end{array}$ & $\begin{array}{l}\text { Post- } \\
\text { surgery }\end{array}$ & $\begin{array}{l}\text { POP } \\
\text { D1 }\end{array}$ & $\begin{array}{l}\text { POP } \\
\text { D2 }\end{array}$ & $\begin{array}{l}\text { POP } \\
\text { D3* }^{*}\end{array}$ & $\begin{array}{l}\text { POP } \\
\text { D7§ }\end{array}$ \\
\hline $\begin{array}{l}\text { Direct antiglobulin } \\
\text { test (DAT) }\end{array}$ & $x$ & $x$ & $x$ & $x$ & $x$ & $x$ & $\mathrm{x}$ & $x$ \\
\hline $\begin{array}{l}\text { Free } \mathrm{Hb} \text { in plasma } \\
\text { and haptoglobin }\end{array}$ & & $x$ & $x$ & $x$ & $x$ & $x$ & $x$ & $x$ \\
\hline $\begin{array}{l}\text { Complement factors: } \\
\text { C3b, TCC }\end{array}$ & & $x$ & $x$ & $x$ & $x$ & $x$ & $x$ & $x$ \\
\hline \multicolumn{9}{|l|}{ Coagulation: } \\
\hline $\begin{array}{l}\mathrm{ACT}^{*}, \text { aPTT, } \\
\text { INR } \mathrm{NR}^{\S} \text {, fibrinogen, } \\
\text { protein } \mathrm{C}^{\S}\end{array}$ & & $x$ & $x$ & $x$ & $x$ & $x$ & $x$ & $x$ \\
\hline
\end{tabular}

$\mathrm{Hb}$, hemoglobin. TCC, terminal complement complex. ACT, activated clotting time. aPTT, activated partial thromboplastin time. INR, international normalized ratio

*Only open heart-surgery study

§Only liver resection study

in group "A-B-AB" and 11 in group "O", whereas 19 patients received Octaplas. Twenty-nine patients were not in need of plasma transfusions. When comparing the clinical profile as well as operative and postoperative data from the four groups, the only significant differences were shorter bypass time and less anticoagulation in the nontransfused patients, while respirator time and circulatory support did not differ significantly. There were no significant differences between groups "A-B-AB", "O" or the Octaplas-transfused patients with respect to plasma or total cellular blood product transfusions. Uniplas transfusions were in the range $3 \pm 3.5$ units (range 1-16) in group "A-B-AB" and $3 \pm 4.4$ units (range 1-23) in group "O". Octaplas transfusions were in the $2.2 \pm 3.5$ units (1-11) range. However, the nonplasma transfused patients received significantly fewer blood products than those who were transfused.

During the study, a total of 55 adverse events were observed in 26 patients, all were assessed as unrelated to plasma transfusion. When adverse events were grouped by organ class according to MedDRA guidelines, no significant differences were observed between the groups. One patient in each Uniplas group and three patients in the Octaplas group underwent a second surgery because of postoperative bleeding. Two patients transfused with Octaplas died intraoperatively due to surgical complications, while five patients died between three weeks and 7 months postsurgery. None of the deaths were related to study design or plasma transfusions.

In the nonplasma transfused patients, complement factor $\mathrm{C} 3$ activation products increased from $9.0 \pm 3.3 \mathrm{AU}$ (arbitrary units) at the start of the surgery to $69.1 \pm 35.3 \mathrm{AU}$ at the end, but returned to preoperative levels at 24 and 48 hours after the operation. Similar changes were observed in the three groups transfused with plasma. These changes did not differ significantly between the four groups. TCC demonstrated a similar pattern with no significant differences between the groups. At the end of the surgeries, activated clotting time was low and demonstrated no differences between the four groups, while aPTT was moderately elevated in all groups. Fibrinogen concentration demonstrated a fall postsurgery with partial recovery after day 2 . Plasma transfusion did not result in DAT changes from negative at baseline to positive or from positive at baseline to stronger reaction, nor did laboratory tests for free hemoglobin in plasma or haptoglobin indicate hemolysis.

Liver resection study ${ }^{21}$

Of the 122 patients enrolled, 81 were transfused with Uniplas at least once, while 41 did not require plasma transfusion. The transfused patients had more complicated types of surgery, a longer duration of surgery and more intraoperative bleeding. Aprotinin was administered to patients who were considered at risk for fibrinolysis ( $48 \%$ in the Uniplas group).

A comparison of groups "A-B-AB" $(\mathrm{n}=58)$ and "O" $(\mathrm{n}=23)$ showed that the indications for liver resection were similar. However, group "A-B-AB" had fewer right hemi-hepatectomies, somewhat shorter duration of surgery and lower volumes of $\mathrm{RBC}$ transfusions $(43 \%, 843 \pm \mathrm{ml}$ compared to $52 \%$, $1099 \pm 567 \mathrm{ml}$ in group "O”). There was no significant difference in Uniplas transfusions between the groups.

The first Uniplas transfusion episode was during surgery in $97.5 \%(79 / 81)$ of the patients. Eleven patients had more than one transfusion episode. The mean body weight adjusted first transfusion dose was $14 \mathrm{ml} / \mathrm{kg}$ and the mean total dose was 18 $\mathrm{ml} / \mathrm{kg}$. A first dose of $\geq 20 \mathrm{ml} / \mathrm{kg}$ was given to 20 patients, and 1 male of blood group A had a first transfusion episode of $50.7 \mathrm{ml} / \mathrm{kg}$. This patient also received the largest total volume, equal to $129.6 \mathrm{ml} / \mathrm{kg}$ (4 transfusion episodes). In spite of the high dose, the patient neither demonstrated positive DAT nor hemolysis. 
Due to loss of 23 samples in a courier shipment to the central laboratory in Germany, DAT could only be evaluated in $65 / 81$ patients after transfusion with Uniplas and 34/41 patients not requiring plasma transfusion. One nontransfused patient and 1 patient transfused with Uniplas demonstrated positive DAT prior to surgery/transfusion and at later timepoints. Three Uniplas transfused blood group B patients with negative DAT before transfusion had a single or intermittent positive DAT. One patient transfused with Uniplas $(27.4 \mathrm{ml} / \mathrm{kg})$, had a positive DAT posttransfusion, but not in subsequent samples. Before analysis, the CPDA blood samples had been stored at $4^{\circ} \mathrm{C}$ to $10^{\circ} \mathrm{C}$ for over a week, which could be a cause for $e x$ vivo fixation of complement. A second patient with a cavernous hemangioma had a negative DAT posttransfusion $(9.6 \mathrm{ml} / \mathrm{kg})$ followed by positive tests postsurgery and on day 1 and day 2 . Testing by specific reagents demonstrated the deposition of $\mathrm{C} 3 \mathrm{c}$, but not $\mathrm{IgM} / \mathrm{IgG}$ or $\mathrm{C} 3 \mathrm{~d}$ on the RBCs. The third patient had a positive DAT first on day 7 after transfusion of Uniplas $(13.3 \mathrm{ml} / \mathrm{kg})$. In none of the three patients did laboratory tests for free hemoglobin in plasma or haptoglobin indicate hemolysis.

During the study a total of 127 adverse events were registered in 51 Uniplas-transfused patients. There was no significant difference in adverse events between the "A-B-AB" and the "O" groups and there were no deaths. No patients experienced fibrinolysis; however, one patient had a possible thromboembolism. The latter patient had a vascular cerebral incident and demonstrated, at that time point, protein $\mathrm{C}$ and $\mathrm{S}$ values of $0.57 \mathrm{U} / \mathrm{ml}$ and $0.66 \mathrm{U} / \mathrm{ml}$, respectively. However, after transfusion of $600 \mathrm{ml}$ Uniplas 58 hours before the incident, protein $\mathrm{C}$ and $\mathrm{S}$ values were in the normal range.

When adverse events were grouped by organ class according to MedDRA, there was no statistical difference between the "A-B-AB" and the "O" groups $(\mathrm{p}=0.44)$. Only two adverse events were classified as possibly (fever after 6 hours) and probably (urticaria after 40 minutes) induced by Uniplas.

Mean baseline and posttransfusion serum samples demonstrated complement activation with high $\mathrm{C} 3 \mathrm{~b}$ and TCC values. However, there was no observable trend of increased posttransfusion activation. Laboratory safety parameters indicated some $\mathrm{RBC}$ destruction in the "O" group, but not in the at risk "A-B-AB" group (table 4).
As expected after liver resection, the values for aPTT and INR increased on days 1 and 2 postsurgery, but recovered to near normal values by day 7 . Fibrinogen concentration demonstrated a fall postsurgery with partial recovery as from day 2. Protein $\mathrm{C}$ values decreased to the lower normal range for the first week postsurgery. However, in patients who received $\geq 20 \mathrm{ml}$ Uniplas $/ \mathrm{kg}$ during one transfusion episode, protein C levels were $0.92 \pm 0.37 \mathrm{IU} / \mathrm{ml}$.

\section{Discussion}

The primary aim of the clinical studies with Uniplas has been to investigate the safety of the product with regard to hemolytic transfusion reactions that could theoretically be caused by low residual amounts of anti-A and anti-B antibodies. Presently, many patients of blood group A, B and $\mathrm{AB}$ receive apheresis platelet transfusions with anti-A and anti-B antibodies from blood group $\mathrm{O}$ donors. ${ }^{5}$ Many of these transfusions result in no detectable transfusion reaction, while others give a positive DAT without signs of hemolysis. ${ }^{24}$ However, serious DAT-positive hemolytic reactions have been reported even after transfusion of only $225 \mathrm{ml}$ of an apheresis product which agglutinated blood group A RBCs at a 1:128 dilution in saline. ${ }^{25}$ DAT was therefore chosen as indicator of immunoglobulin and complement binding to RBCs, while hemolysis was evaluated by free hemoglobin and haptoglobin in serum.

The DAT results in the open-heart surgery studies demonstrated no changes from negative baseline DAT to positive posttransfusion, or from initially positive to stronger reaction after transfusion. In the liver resection study, a nontransfused and a Uniplas-transfused patient who demonstrated positive DAT before surgery and transfusion, were excluded from evaluation, because the DAT reaction strength was not graded. Three blood group B patients with baseline negative DATs changed to single or intermittently positive DATs after transfusion. One patient with a positive DAT in the first sample after plasma transfusion $(27.4 \mathrm{ml} / \mathrm{kg})$ demonstrated negative DAT in following samples. Storage of the positive sample at $5^{\circ} \mathrm{C}$ to $10^{\circ} \mathrm{C}$ as CPDA blood for over a week prior to DAT and the lack of laboratory signs of hemolysis support the possibility for ex vivo binding of complement to the RBCs in this patient. In the second patient transfused with $9.6 \mathrm{ml} / \mathrm{kg}$ posttransfusion, DAT was negative. However, the postsurgery and day 1 and day 2 tests were

Table 4. Pre- and posttransfusion tests for hemolysis

\begin{tabular}{|c|c|c|c|c|c|c|}
\hline \multirow[b]{2}{*}{ Plasma test } & \multirow[b]{2}{*}{$\mathbf{N}$} & \multicolumn{2}{|c|}{ Group A, B and AB } & \multicolumn{3}{|c|}{ Group 0} \\
\hline & & $\begin{array}{l}\text { Pretransfusion } \\
\text { mean } \pm \text { SD }\end{array}$ & $\begin{array}{c}\text { Posttransfusion } \\
\text { mean } \pm \text { SD }\end{array}$ & $\mathbf{N}$ & $\begin{array}{l}\text { Pretransfusion } \\
\text { mean } \pm S D\end{array}$ & $\begin{array}{c}\text { Posttransfusion } \\
\text { mean } \pm \text { SD }\end{array}$ \\
\hline $\begin{array}{l}\text { Free } \mathrm{Hb} \\
(\mathrm{mg} / \mathrm{l})\end{array}$ & 69 & $95.69 \pm 153.3$ & $88.71 \pm 105.02$ & 27 & $142.79 \pm 236.67$ & $193.22 \pm 294.94$ \\
\hline $\begin{array}{l}\text { Haptoglobin } \\
(\mathrm{g} / \mathrm{l})\end{array}$ & 69 & $1.02 \pm 0.68$ & $0.86 \pm 0.62$ & 27 & $1.32 \pm 0.83$ & $1.11 \pm 0.82$ \\
\hline
\end{tabular}

$\mathrm{Hb}$, hemoglobin. $\mathrm{N}$, number of patients in group. SD, standard deviation

$214 \quad$ Universal SD-treated plasma

$C M \& R 2006: 3$ (September) 
positive. Further analysis demonstrated $\mathrm{C} 3 \mathrm{c}$ and not $\mathrm{C} 3 \mathrm{~d}$ or IgG/IgM, which would be expected after sensitization with anti-A or anti-B antibodies. This patient had a liver resection for a cavernous hemangioma with atypical vascular bed, which can lead to $\mathrm{C} 3 \mathrm{c}$ activation and sensitization of RBCs. These RBCs are released during surgery and could explain a positive DAT postsurgery and on the following two days. In the last patient, a positive DAT was first observed seven days after a single Uniplas transfusion episode of $13.3 \mathrm{ml} / \mathrm{kg}$, which rules out any association with plasma. Thus, a positive DAT caused by transfusion of Uniplas is unlikely in the first patient due to possible ex vivo complement binding to RBCs and can be ruled out in the last two patients. It should also be pointed out that in the patient with blood group A, DAT remained negative after a Uniplas transfusion episode of 50.7 $\mathrm{ml} / \mathrm{kg}$ and a total transfusion volume of $129.6 \mathrm{ml} / \mathrm{kg}$. Neither the DAT-positive nor the other patients transfused with Uniplas demonstrated changes in free hemoglobin in plasma or haptoglobin, which were attributable to plasma transfusion. Therefore, it can reasonably be concluded that Uniplas did not elicit hemolytic transfusion reactions.

Complement activation was investigated to monitor possible immunological or biological incompatibility of Uniplas. In the open-heart surgery studies, there was no increase over that normally seen during extracorporeal circulation after Uniplas or Octaplas transfusion. In the liver resection study, mean values of $\mathrm{C} 3 \mathrm{~b}$ and $\mathrm{TCC}$ were significantly increased at most sampling time points both in patients transfused with Uniplas and in those not in need of plasma. Even allowing for some degree of liver impairment, the results were highly unlikely and indicate inadequate handling of the samples combined with the use of serum instead of EDTA-plasma. Thus, an interpretation of the complement analysis remains elusive in the liver resection study, although no trends of increased complement activation were observed after Uniplas transfusion. In conclusion, the two clinical studies indicate that Uniplas does not cause complement activation.

In the open-heart surgery study, Uniplas demonstrated a satisfactory effect, similar to Octaplas, in the treatment of bleeding with no significant difference in chest drainage, activated clotting time or aPTT. In the liver resection study pre- and posttransfusion aPTT and INR levels were similar and only slightly elevated, and after transfusion of $\geq 20 \mathrm{ml} / \mathrm{kg}$, the protein $\mathrm{C}$ levels were normal. These results are in accordance with prospective, randomized and observational studies demonstrating a similar effect of European SD-treated plasma and fresh-frozen plasma. ${ }^{16}$ None of the patients demonstrated fibrinolysis. However, aprotinin was used in liver resection patients who were at risk for fibrinolysis. Aprotinin is a serine esterase inhibitor that can replace plasmin inhibitor, the liver-synthesized acute phase serine esterase inhibitor that is reduced by $70 \%$ in Uniplas and Octaplas due to SD treatment. ${ }^{26}$ One case of possible thromboembolism (in the liver resection study) was a vascular cerebral incident which happened after Uniplas administration. At the time point of the incident both the protein $\mathrm{C}$ and $\mathrm{S}$ values were in the low normal range $(0.57$ $\mathrm{IU} / \mathrm{ml}$ and $0.66 \mathrm{IU} / \mathrm{ml}$ respectively). However, the two values were normal after Uniplas transfusion 58 hours prior to the incident. The observed safety of Uniplas, with respect to fibrinolysis and thromboembolism, is in accordance with experience with Octaplas. ${ }^{15}$ In Europe, a retrospective study has raised concerns about venous thromboembolism in patients with thrombotic thrombocytopenic purpura who had plasma exchange with Octaplas. ${ }^{27}$ This could be attributed to the fact that protein $\mathrm{S}$ is reduced to the lower normal range in Octaplas and Uniplas. However, neither randomized nor observational studies with Octaplas have reported any clinical significance of the reduced protein S level. ${ }^{16}$ Uniplas has now received orphan drug designation for the treatment of thrombotic thrombocytopenic purpura in the US, and in Canada, a randomized controlled trial comparing plasma exchange with Uniplas versus cryo-supernatant plasma is currently under way. ${ }^{28}$ This should determine the significance of reduced protein $\mathrm{S}$ levels associated with Uniplas or Octaplas administration in thrombotic thrombocytopenic purpura.

According to product specification, anti-A and anti-B antibody titers in Uniplas are one titer step lower $(\operatorname{IgM}<8$ and $\operatorname{IgG}<32$ ) than accepted for intravenous immunoglobulins (IVIg) by the European Pharmacopoeia ( $<64$ for 3\% IVIg) and several steps lower than for apheresis platelets where a titer of $<250$ is accepted. ${ }^{29,30}$ For IVIg, a dose of $40 \mathrm{ml} / \mathrm{kg}$ of a $3 \%$ solution is accepted per infusion episode, while an apheresis platelet transfusion episode seldom exceeds $10 \mathrm{ml} / \mathrm{kg}$. In Norway, no adverse reactions have been reported after the requirement of an anti-A/anti-B IgM/IgG titer $<250$ was introduced in 1995 for apheresis platelets containing such antibodies reactive with a recipient's RBCs. ${ }^{29,30}$ The observation that a Uniplas transfusion episode of $50.7 \mathrm{ml} / \mathrm{kg}$ was well tolerated in a blood group A patient is thus in agreement with the experience with IVIg and apheresis plasma.

\section{Conclusion}

The presented clinical studies indicate that Uniplas is a safe product that can be administered irrespective of a patient's $A B O$ blood group, to well above a clinically adequate dose of 20 $\mathrm{ml} / \mathrm{kg}$. This is important as serious harm from blood products is most commonly caused by failures in the process of ordering, delivery or administration. 1,2,6,31,32,33 Uniplas will reduce this problem by simplifying the logistics and eliminating of the need for ABO-matched plasma. This is in accordance with the South African experience of transfusing $>300,000$ units of their universal, ABO-independent, SD-treated, freeze-dried plasma, Bioplasma FDP. ${ }^{9}$ The identical production process should ensure that Uniplas demonstrates the same safety with respect to transfusion-related acute lung injury and febrile, urticarial and anaphylactoid reactions as Octaplas. $34,35,36,37$

Cost-effectiveness of pathogen reduction is low in the developed world due to the very low risk of transfusion transmittable 
infections after introduction of modern methods for the detection of infectious agents. ${ }^{29}$ High cost per quality-adjusted life year estimates of US \$2-9 million have been published for SD-treated plasma. ${ }^{38,39}$ If, however, noninfective transfusion-related complications are included in the calculations, significantly more favourable estimates are obtained for this product. Cost-effectiveness for Octaplas of US $\$ 40,000$ to $\$ 100,000 /$ life year saved have been demonstrated when transfusion-related acute lung injury is included in the calculations. ${ }^{40}$ For Uniplas, which potentially eliminates the risk of ABO-incompatibility, the cost-effectiveness is even more favourable due to the additional benefit of emergency use and simplified logistics.

\section{References}

1. Stainsby D. Haemovigilance in the United Kingdom and Europe. Hematol J 2004;5:S175-S178.

2. Henderson RA, Pinder L. Acute transfusion reactions. N Z Med J 1990;103:509-511.

3. College of American Pathologist. Transfusion medicine survey (J-A). 2005.

4. Spalter SH, Kaveri SV, Bonnin E, Mani JC, Cartron JP, Kazatchkine MD. Normal human serum contains natural antibodies reactive with autologous $\mathrm{ABO}$ blood group antigens. Blood 1999;93:4418-4424.

5. McManigal S, Sims KL. Intravascular hemolysis secondary to ABO incompatible platelet products. An underrecognized transfusion reaction. Am J Clin Pathol 1999;111:202-206.

6. Baele PL, De Bruyere M, Deneys V, Dupont E, Flament J, Lambermont M, Latinne D, Steensens L, van Camp B, Waterloos H. Bedside transfusion errors. A prospective survey by the Belgium SAnGUIS Group. Vox Sang 1994;66:117-121.

7. Flesland O, Seghatchian J, Solheim BG. The Norwegian Plasma Fractionation Project - a 12 year clinical and economic success story. Transfus Apher Sci 2003;28:93-100.

8. HMSO: Dried human plasma. HMSO, London; 1973.

9. Chapanduka ZC, Fernandes-Costa FJ, Rochat C, Blyth DF. Comparative safety and efficacy of Bioplasma FDP versus single-donor fresh-dried plasma in cardiopulmonary bypass patients. S Afr Med J 2002;92:356-357.

10. Horowitz B, Bonomo R, Prince AM, Chin SN, Brotman B, Shulman RW. Solvent/detergent-treated plasma: a virus-inactivated substitute for fresh frozen plasma. Blood 1992; 79:826-831.

11. Biesert L, Suhartono H. Solvent/detergent treatment of human plasma - a very robust method for virus inactivation. Validated virus safety of OCTAPLAS. Vox Sang 1998;74 (suppl 1):207-212.

12. Solheim BG, Rollag H, Svennevig JL, Arafa O, Fosse E, Bergerud U. Viral safety of solvent/detergent-treated plasma. Transfusion 2000;40:84-90.

13. Solheim BG, Hellstern P. Composition, efficacy, and safety of S/D-treated plasma. Transfusion 2003;43:1176-1178.

14. Salge-Bartels U, Breitner-Ruddock S, Hunfeld A, Seitz R, Heiden M. Are quality differences responsible for different adverse reactions reported for SD-plasma from USA and Europe? Transfus Med 2006;16:266-275.

15. Hellstern P. Solvent/detergent-treated plasma: composition, efficacy, and safety. Curr Opin Hematol 2004;11:346-350.

16. Hellstern P, Haubelt H. Manufacture and composition of fresh frozen plasma and virus-inactivated therapeutic plasma preparations: correlation between composition and therapeutic efficacy. Thromb Res 2002;107:S3-S8.

17. Beeck H, Hellstern P In vitro characterization of solvent/detergent-treated human plasma and of quarantine fresh frozen plasma. Vox Sang 1998;74(suppl 1):219-223.
18. Heger A, Romisch J, Svae TE. Stability of solvent/detergent-treated plasma and single-donor fresh-frozen plasma during $48 \mathrm{~h}$ after thawing. Transfus Apher Sci 2005;33:257-267.

19. Noddeland H, Tollofsrud S, Svennevig J, Bentsen G, Brosstad F, Solheim B. Universal solvent/detergent-treated fresh frozen plasma (Uniplas) - rationale and clinical properties. Thromb Res 2002;107:S33-S37.

20. Tollofsrud S, Noddeland H, Svennevig JL, Bentsen G, Mollnes TE, Solheim BG. Universal fresh frozen plasma (Uniplas): a safe product in open-heart surgery. Intensive Care Med 2003;29:1736-1743.

21. Solheim BG, Granov DA, Juravlev VA, Krawczyk M, Kubishkin VA, Patutko UI, Raab R. Universal fresh-frozen plasma (Uniplas): an exploratory study in adult patients undergoing elective liver resection. Vox Sang 2005;89:19-26.

22. Garred P, Mollnes TE, Lea T. Quantification in enzyme-linked immunosorbent assay of a $\mathrm{C} 3$ neoepitope expressed on activated human complement factor C3. Scand J Immunol 1988;27:329-335.

23. Mollnes TE, Lea T, Froland SS, Harboe M. Quantification of the terminal complement complex in human plasma by an enzyme-linked immunosorbent assay based on monoclonal antibodies against a neoantigen of the complex. Scand J Immunol 1985;22:197-202.

24. Shanwell A, Ringden O, Wiechel B, Rumin S, Akerblom O. A study of the effect of $\mathrm{ABO}$ incompatible plasma in platelet concentrates transfused to bone marrow transplant recipients. Vox Sang 1991;60:23-27.

25. Mair B, Benson K. Evaluation of changes in hemoglobin levels associated with $\mathrm{ABO}$-incompatible plasma in apheresis platelets. Transfusion 1998;38:51-55.

26. Solheim BG, Bergan A, Brosstad F, Innes R, Svennevig JL. Fibrinolysis during liver transplant and use of solvent/detergent virus-inactivated plasma (ESDEP/Octaplas). Anesth Analg 2003;96:1230-1231.

27. Yarranton H, Cohen H, Pavord SR, Benjamin S, Hagger D, Machin SJ. Venous thromboembolism associated with the management of acute thrombotic thrombocytopenic purpura. Br J Haematol 2003;121:778-785.

28. Rock G, Clark B, Sutton D; CAG; CAAN. The Canadian apheresis registry. Transfus Apher Sci 2003;29:167-177.

29. Solheim BG, Seghatchian J. What is happening. Update on pathogen reduction technology for therapeutic plasma: An overview. Transfus Apheresis Sci 2006 (in press).

30. [No authors listed]. Transfusion of apheresis platelets and ABO groups. Vox Sang 2005;88:207-221.

31. Myhre BA, McRuer D. Human error-a significant cause of transfusion mortality. Transfusion 2000;40:879-885.

32. Linden JV, Wagner K, Voytovich AE, Sheehan J. Transfusion errors in New York State: an analysis of 10 years' experience. Transfusion 2000;40:1207-1213.

33. Krombach J, Kampe S, Gathof BS, Diefenbach C, Kasper SM. Human error: the persisting risk of blood transfusion: a report of five cases. Anesth Analg 2002;94:154-156.

34. Bux J. Transfusion-related acute lung injury (TRALI): a serious adverse event of blood transfusion. Vox Sang 2005;89:1-10.

35. Sinnott P, Bodger S, Gupta A, Brophy M. Presence of HLA antibodies in single-donor-derived fresh frozen plasma compared with pooled, solvent detergent-treated plasma (Octaplas). Eur J Immunogenet 2004;31:271-274.

36. Sachs UJ, Kauschat D, Bein G. White blood cell-reactive antibodies are undetectable in solvent/detergent plasma. Transfusion 2005;45:1628-1631.

37. Solheim BG. Plasma-induced TRALI is avoided with solvent/detergent-treated plasma [abstract]. Transfusion Alternatives in Transfusion Medicine 2005;7(suppl):57. Abstract P16. 
38. Pereira A. Cost-effectiveness of transfusing virus-inactivated plasma instead of standard plasma. Transfusion 1999;39:479-487.

39. Jackson BR, AuBuchon JP, Birkmeyer JD. Update of cost-effectiveness analysis for solvent-detergent-treated plasma. JAMA 1999;282:329.

40. Riedler GF, Haycox AR, Duggan AK, Dakin HA.

Cost-effectiveness of solvent/detergent-treated fresh-frozen plasma. Vox Sang 2003;85:88-95.

\section{Author Affiliation}

Bjarte G. Solheim, MD, PhD, MHA, Institute of

Immunology, Rikshospitalet - Radiumhospitalet Medical

Center, University of Oslo, NO-0027 Oslo, Norway 